\title{
EL AJUAR FUNERARIO DE LOS GOBERNANTES DEL CLÁSICO COMO EXPRESIÓN DEL COSMOS EN EL UNIVERSO MAYA
}

\author{
VERdjINA BAjKOVA \\ Instituto de Investigaciones Antropológicas y Facultad de Filosofía y Letras, \\ Universidad Nacional Autónoma de México
}

\begin{abstract}
Resumen: Los gobernantes mayas estilaban utilizar atavíos funerarios para expresar su poder después de la muerte. La diversidad de contextos puede ir desde un uso religioso, mágico, elemento de culto o simplemente para expresar su belleza física. Tales atavíos se elaboraron con jade y otros materiales preciosos, que sin duda tuvieron una gran carga simbólica entre los mayas. Desde la antiguiedad ha existido la asignación de valores metafóricos a las prendas respecto a su posición en el cuerpo humano; así como los artefactos asociados a las manos pueden indicar implementos de acción, las prendas vinculadas con la cabeza adquieren, junto con ella, una posición sobresaliente y esencial. Integrándose al rostro, éstas contribuyen a portar valores de identidad, ya sea a nivel individual o colectivo. Dichas prendas resultaban indispensables en ciertas actividades públicas y ceremoniales, atestiguando la pertenencia a un grupo social e incluso validando la posesión de poder y sacralidad de una persona. Todo esto confirma que estamos ante una sociedad de gran complejidad, y que las elites mayas del periodo Clásico utilizaban símbolos de poder representados en los atavíos para presentarse como integrantes de un linaje poderoso.
\end{abstract}

Palabras clave: atavíos mayas, objetos de jade, gobernantes, muerte, ritual.

ABSTRACT: For the Maya rulers was fundamental the use of funerary attires to express their power after death. The diversity of contexts can range from a religious use, magical, element of worship or simply to express their physical beauty. The materials that were made of was jade and other precious materials, it definitely had a great symbolic meaning among the Maya. Since ancient times have existed metaphorical values of the garments and their position on the human body. The artifacts associated with the hands indicated action; the garments associated with the head along with it acquire outstanding and essential position. Integrating them with the face, they represent identity values, either individually or collectively. These garments are essential in certain public and ceremonial activities, attesting to membership of a social group and even validating the possession of power and sacredness of a person. All this implies that we have a very complex society, so that the elite Classic Maya used symbols of power represented as attires with one cause to be presented as a powerful lineage.

KeYwords: attire, jade objects, rulers, death, ritual.

RECEPCIÓn: 4 de noviembre de 2013.

ACEPTACIÓN: 6 de abril de 2014. 



\title{
EL AJUAR FUNERARIO DE LOS GOBERNANTES DEL CLÁSICO COMO EXPRESIÓN DEL COSMOS EN EL UNIVERSO MAYA
}

\author{
VERDJinA BAJKOVA \\ Instituto de Investigaciones Antropológicas y Facultad de Filosofía y Letras, \\ Universidad Nacional Autónoma de México
}

Es objetivo del presente trabajo es argumentar que los ajuares funerarios han sido utilizados a través del tiempo como un indicador social, en tanto los grupos dirigentes se han distinguido por portar elaborados atuendos y joyas cuyo valor radica no sólo en la selección de materiales preciados para su fabricación, sino en el uso de emblemas y otros símbolos destinados a testimoniar supremacía. Con tal objetivo en mente, abordaremos lo concerniente a los atavíos funerarios de la elite maya en tres sitios del periodo Clásico: Dzibanché, Palenque y Calakmul.

En agosto de 1994, Enrique Nalda descubrió una tumba en el Templo del Búho o Templo I de Dzibanché, Quintana Roo. Dicha tumba (D/A-1/5), fechada como del Clásico Temprano (250-450 d.C.), se ubica en un edificio de plataformas con una gran cámara abovedada. El personaje de la tumba, probablemente una mujer de mediana edad, debía estar sentado con las piernas y los brazos entrecruzados, y todo su cuerpo cubierto con cinabrio. Portaba un par de orejeras de jade, un largo collar de concha y jade y una cuenta de jade en la boca, a más de incrustaciones del mismo material en sus dientes. La ofrenda, con material del Clásico Temprano, incluía vasijas de alabastro y de cerámica policroma, ${ }^{1}$ navajas prismáticas de obsidiana verde, un collar de caracoles perforados, un espejo hecho con un material mineral no identificado, y una tablilla de madera estucada, con dibujos tipo códice. Las piezas más relevantes de la tumba son una concha (de tipo Spondylus y con incrustaciones de jade) con perlas naturales, que se portaba como pectoral, un elaborado tocado y una barra con la representación de una serpiente bicéfala que llevaba el personaje en las manos.

Las tumbas de los gobernantes mayas se encuentran cerca de los edificios superiores o selladas bajo el nivel de desplante del basamento, de tal manera que sólo es posible llegar a ellas mediante riesgosas exploraciones (Campaña, 1995).

Por otra parte, en el Templo de las Inscripciones de Palenque, como es bien sabido, se encuentra la tumba (muknal) de K'inich Janaab' Pakal, fechada en el año de 683 d.C. y descubierta en 1952 por Alberto Ruz Lhuillier. La estructura

\footnotetext{
${ }^{1}$ Un tipo de cerámica policroma con variantes desde Dos Arroyos hasta el Petén.
} 


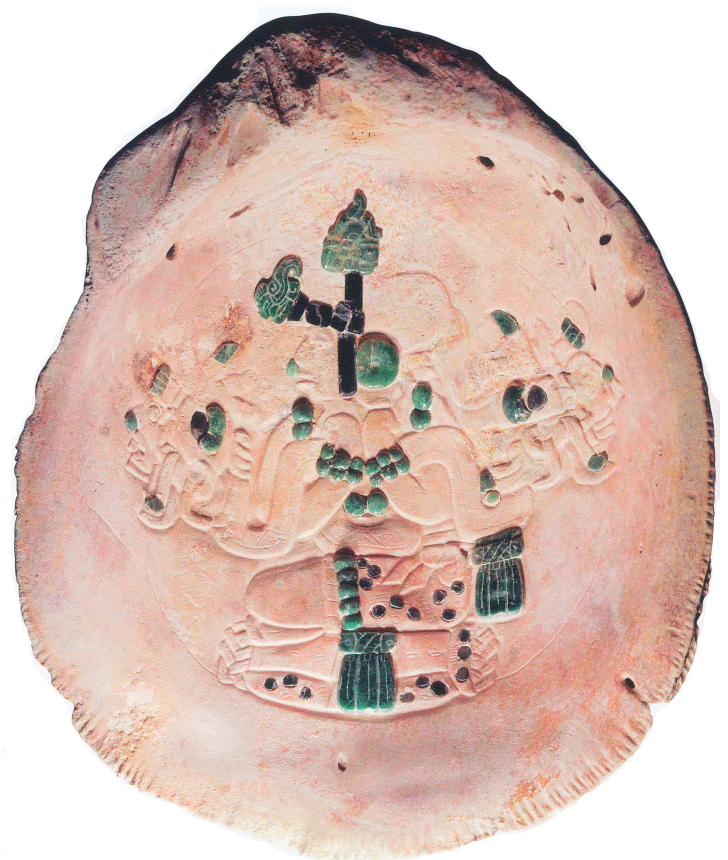

FiguRA 1. La concha con relieve e incrustación de la tumba del gobernante femenino (Fields y Reents-Budet, 2005: 168).

piramidal del Templo de las Inscripciones exhibe nueve cuerpos, número que alude a los niveles que, de acuerdo con las creencias mayas, tenía el inframundo (Bernal, 2004). El templo es, pues, réplica arquitectónica de ese ámbito. La cámara funeraria fue decorada con nueve guerreros, los regentes del inframundo, que custodiaron el sarcófago de Pakal durante más de un milenio.

Las honras funerarias de K'inich Janaab' Pakal estuvieron a cargo de su primogénito y heredero al trono, K'inich Kan B'ahlam. El ajuar funerario incluía textiles y una gran variedad de ornamentos, particularmente de jade: anillos, ajorcas, collares, orejeras, un pectoral, una diadema y una extraordinaria máscara, fiel retrato del gobernante fallecido. Junto a sus pies se colocó una pequeña estatua del dios del maíz, labrada también en jadeíta (Ruz Lhuillier, 1973). Este material, que simbolizaba el agua, el verdor de la naturaleza y, en general, la fertilidad, fue la expresión pétrea, de la renovación de la vida.

El cuerpo fue cubierto con cinabrio, mineral de intenso color rojo que representaba el líquido vital por excelencia: la sangre. El cinabrio y la jadeíta abundan dentro de las tumbas de la elite maya, lo que algunos autores han considerado podría apuntar a que se creyera que transferían sus cualidades regenerativas al gobernante fallecido, quien experimentaba una especie de resurrección (Tiesler y Cucina, 2003). 


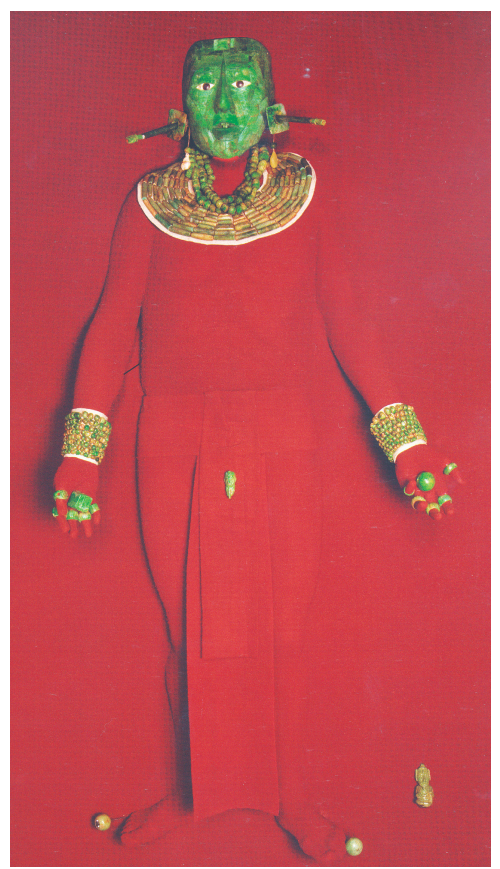

FiguRA 2. El atavío funerario de K’inich Janaab' Pakal (Martínez del Campo, 2010: 227).

Por lo que concierne a Calakmul, Campeche, nos detendremos en la tumba 4 de la subestructura II, ubicada en el eje central del sitio y descubierta entre 1997 y 1998 por el arqueólogo Ramón Carrasco. La cámara principal de la tumba, fechada hacia 700 d.C., con una bóveda en saledizo, fue aplanándose con lodo para simular una bóveda de cañón corrido. Las paredes fueron pintadas en varios colores y tenían glifos que simbolizaban el inframundo o puentes entre lo terrestre y lo celeste. En la cámara principal se encontró el cuerpo del gobernante Garra de Jaguar, Yuknoom Yich' aak K'ahk', quien descansaba sobre una lujosa parihuela de madera decorada con flores. Su atavío era de concha, un ex o braguero de algodón decorado con conchas Spondylus en forma de flores, un par de orejeras y dos collares de jadeíta y perlas. Entre sus muslos se colocó una esponja marina.

El cuerpo fue decorado con varios métodos, en un proceso que duraba varias semanas. Después de preparar el bulto mortuorio, el cuerpo se atavió con la vestimenta característica de un ajaw, se colocaron las joyas y al final una máscara de jadeíta sobre madera, de calidad extraordinaria, y un segundo par de orejeras con inscripciones en su interior. A sus pies se pusieron otras valvas Spondylus y una ofrenda de cerámica policroma, y alrededor de la cabeza un coral y un tocado de palma y estuco con mosaico de jadeíta, concha nácar y una garra de jaguar, que denotaban su calidad de divino señor (Carrasco, 1999). 


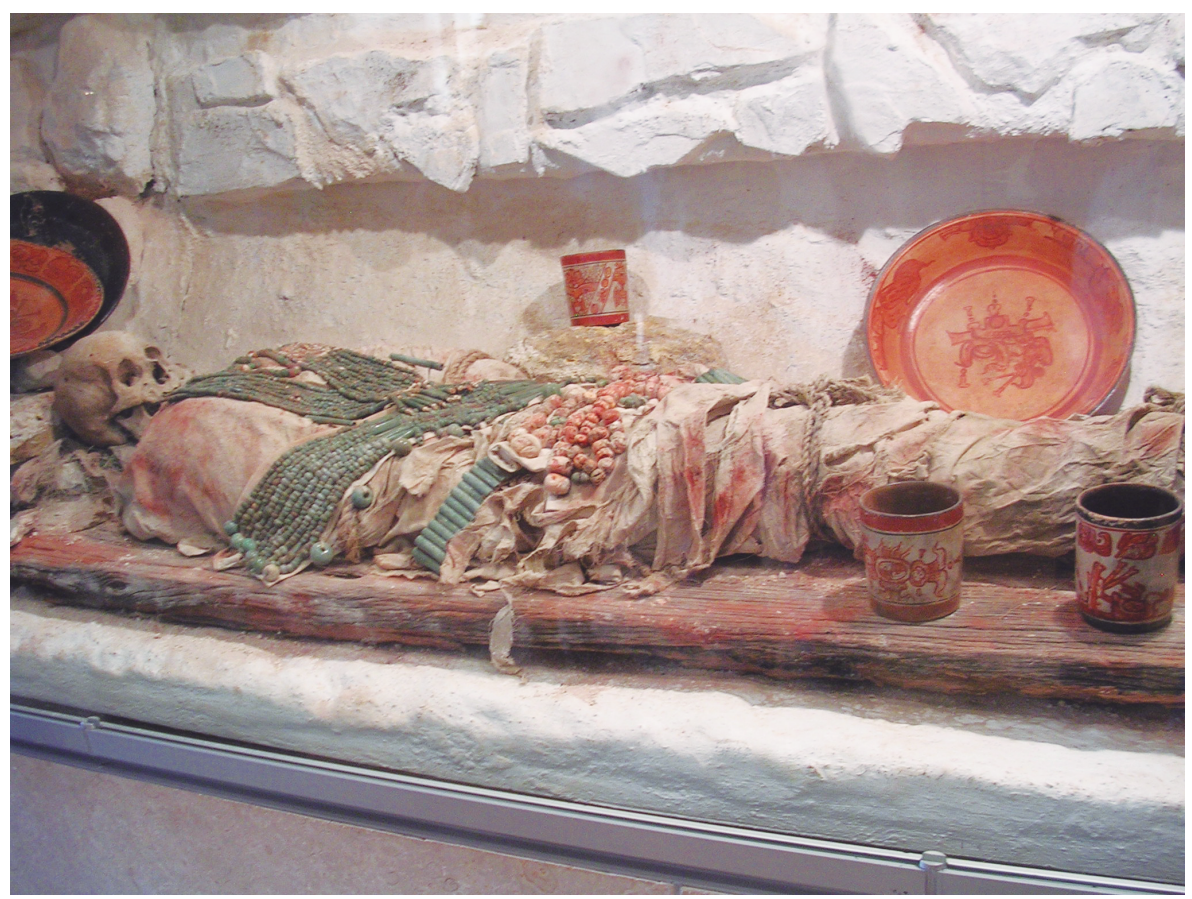

FIGURA 3. Yuknoom Yich'aak K'ahk' Garra de Jaguar

(Fotografía de Roberto Romero Sandoval, 2006).

Cabe señalar que no sólo los casos presentados exhiben atavío funerario; éste figura en todas las tumbas de los gobernantes mayas en el periodo Clásico (200900 d.C.), como lo muestran sitios como Copán, Tikal y Oxkintok, entre otros.

\section{Simbología}

\section{Dzibanché}

La riqueza de las ofrendas y su atavío funerario del gobernante femenino en esa pequeña cámara indican la relevancia del personaje sepultado, un ajaw del Clásico Temprano.

Los dignitarios mayas aparecen retratados en plenitud con todos los elementos del ajuar como una manifestación del cosmos en el poder temporal, dado que las prendas con cuentas y adornos de jade y concha los convertían en el medio a través del cual fluía la energía del cosmos (Freidel, Schele y Parker, 2001).

Es común suponer una función funeraria para los edificios donde se les colocaba, pero también es frecuente inferir que los basamentos piramidales que soportan templos son volúmenes sólidos y mampostería, que tienen como única 
función elevarlos sobre el nivel de la plaza. El Templo de las Inscripciones, en Palenque, con un basamento que protege y a la vez conduce a la cripta de Pakal, ha sido considerado una excepción a esa regla, si bien el Templo del Búho, en Dzibanché, tampoco parece atenerse a ese concepto de forma y función (Campaña, op. cit.).

Dzibanché había tenido un papel protagónico en el ambiente de belicismo generalizado de la Tierras Bajas del sur durante el Clásico Temprano. Hacia finales de ese periodo, y a juzgar por los textos jeroglíficos grabados en varios bloques de la escalera encontrados en el Edificio de los Cautivos, se involucró en la conquista de pueblos vecinos. No sabemos si esas conquistas las hicieron por cuenta propia o en nombre de otro sitio, pero de ser lo primero, entonces Dzibanché habría sido por un tiempo —-más de un siglo — el asiento de la dinastía Kaan. Hasta ahora se creía que esta dinastía, que en los textos mayas se representa con una cabeza de serpiente, era de Calakmul (Nalda y Balanzario, 2005).

La presencia temprana de los textos de Dzibanché y la de los de Calakmul obliga, por tanto, a buscar interpretaciones alternativas del glifo de la cabeza de serpiente.

La carencia de menciones de los gobernantes de Kanal en las inscripciones tempranas de Calakmul, condujo a Martin y Grube (2002: 103) a sospechar que 'las estelas de este periodo fueron enterradas o destruidas posteriormente, o bien Calakmul no albergaba a la dinastía gobernante en esa época'. Este hecho levanta la posibilidad de que hayan existido reinos con capitales rotativas. Con una interpretación distinta, Beliaev y Safronov (2002: 2) también llegaron a la conclusión de que, durante el Clásico Medio, el centro del reino de Kanal estuvo situado en Dzibanché. Debemos dejar abierta la posibilidad, desde luego, de que las menciones de los señores de Kanal hayan estado escritas en monumentos tempranos de Calakmul que hoy están perdidos, destruidos o erosionados (Velázquez, 2004: 101, nota 37).

La interpretación de la iconografía en la concha plantea un reto sólo en el sentido de que únicamente puede ser discutida en términos generales. La forma familiar en que el gobernante lleva una serpiente en sus manos tiene relación con el conjuro a dioses y antepasados, y era quizás el símbolo básico del ritual regio a lo largo del periodo Clásico. Por desgracia ningún glifo proporciona los detalles que desearíamos conocer acerca de la época del objeto y la identidad de la figura, pero existe una pista sugerente en el tocado del gobernante, que requiere mayor investigación y consideración: es el signo ajaw con hojas encima de la cabeza del gobernante, que acaso pueda ser interpretado como un nombre o parte de él. Se repite en otras inscripciones e iconografías mayas, y se asocia con los primeros años de la historia dinástica citada en Tikal y Copán, entre otros sitios. Existe la posibilidad que éste sea el retrato de un rey, que, sin ser el mismo "héroe" histórico, se atavió con un traje que evocaba a un antiguo predecesor en su cargo real (Stuart, 2004).

En la cámara principal del Templo del Búho está, pues, sepultado un WakahChan, El Árbol del Mundo, o un ajaw del Clásico Temprano, sentado en un trono cubierto con una piel de jaguar y usando la banda frontal de Hu'unal y el tocado de tres hojas. 
Dependiendo del señorío, el ajuar mostraba ciertas particularidades de estilo, pero mantenía el significado ritual de la transformación. Para este fin el gobernante fallecido era ataviado con un ajuar funerario compuesto por elementos que habían formado parte del ajuar o ajuares que acostumbraba portar en vida. En su mayoría estas piezas eran manufacturadas con materiales como jade, concha, obsidiana, hueso y espinas para los sacrificios; se utilizaba cerámica para fabricar los contenedores de alimentos, bebidas y esencias rituales.

En relación directa con el acontecimiento labrado en la piedra del sarcófago de K'inich Janaab' Pakal se inscribió un texto que refrenda al soberano inhumado como axis mundi, considerado por los mayas el centro de la creación y al que, por lo general, representaban como una enorme ceiba o como una planta de maíz cuyas mazorcas poseen en ocasiones el perfil del rostro del dios del maíz, conocido en Palenque como Na-Te'-K'an, "Primer Árbol Precioso" o "Primer Árbol Amarillo" (Freidel, Schele y Parker, op. cit.).

Es de suponer que, en concordancia con la cosmovisión maya, se pensaba que algunas de las teselas constitutivas de los mosaicos contenían la esencia del dignatario, por haber sido elaboradas a partir de objetos usados por él durante su vida. De hecho, aún perdura la antigua creencia mesoamericana que concede a la esencia del alma la cualidad de permanecer en los restos físicos del cuerpo, así como en la vestimenta y los objetos utilizados por el individuo (Martínez del Campo, 2010).

En el interior de la estructura piramidal, en la cripta funeraria, se depositó el cuerpo del "Sagrado Señor", adornado con objetos de jade que lo refrendan como dios del maíz y árbol del mundo, en uno de los acontecimientos funerarios de mayor relevancia durante el periodo Clásico Tardío. Su cuerpo adornado fue cubierto con cinabrio mezclado con hematita, en una constante referencia a la sangre, considerada por los mayas como el agua del inframundo.

Sin embargo, será gracias al análisis interdisciplinario de los vestigios arqueológicos que podremos obtener datos concretos, comparables a nivel regional, tanto en lo relativo a los materiales empleados como en el mensaje iconográfico.

\section{Calakmul}

Como ya se señaló, el ajuar mortuorio de Garra de Jaguar Yuknoom Yich'aak K'ahk' está compuesto por máscaras, collares, anillos, brazaletes, petos, pectorales y figurillas ceremoniales colocados junto al cadáver, así como conchas y caracoles. En esta muestra se puede ver una similitud con el contenido de la tumba de Pakal, y la reproducción del ajuar funerario en la lápida del sarcófago deja ver a detalle las imágenes iconográficas grabadas en la piedra y su significado.

Se trata de estructuras complejas que soportan, en mayor o menor cantidad, diversos elementos con los que se componen complejos discursos simbólicos. Algunos de los motivos son recurrentes en los diferentes atavíos, pero su dispo- 
sición, tamaño y forma de representación adquieren valores únicos en cada caso. Así, es indudable que las innumerables asociaciones específicas de máscaras, así como las figuras humanas, zoomorfas y geométricas estaban altamente codificadas. Asimismo, parece que los materiales pudieron haber sido seleccionados cuidadosamente para su fabricación, no sólo por sus cualidades prácticas y estéticas, sino por el valor simbólico asignado a la materia a través de su origen y/o de sus características físicas.

\section{Los gobernantes mayas y sus atavíos funerarios: similitudes y diferencias}

Desde la antigüiedad ha existido la asignación de valores metafóricos a las prendas respecto a su posición en el cuerpo humano. Así como los artefactos asociados a las manos pueden indicar implementos de acción, las prendas relacionadas a la cabeza adquieren, junto con ella, una posición sobresaliente y esencial. Integrándose al rostro, éstas contribuyen a portar valores de identidad, ya sea a nivel individual o colectivo. Dichas prendas resultan indispensables en ciertas actividades públicas y ceremoniales, atestiguando la pertenencia a un grupo social e incluso validando la posesión de poder y sacralidad de una persona. Todo esto implica que estamos ante una sociedad de gran complejidad, y que los gobernantes mayas del periodo Clásico utilizaban símbolos de poder representados en los atavíos para presentarse como miembros de un linaje poderoso. En este caso el gobernante maya y su atavío funerario de "piedra verde", hecho de elementos particulares, formaban un universo particular, una conexión entre el inframundo y el mundo exterior, un "psicoducto" entre los antepasados y sus descendientes.

El universo metafórico presente en el ritual de enterramiento llega así hasta nosotros de forma tangible; vestigios de épocas pasadas que han de considerarse verdaderas obras de arte, de exquisita manufactura, y fuente de acercamiento a esa antigua civilización. Son hallazgos que forman parte fundamental de ese universo en vista de que en el mundo prehispánico el papel del rostro, y en general de la cabeza, era de suma importancia, en tanto que para la sociedad mesoamericana la cabeza era la parte del cuerpo donde podía exhibirse la jerarquía de hombres y mujeres, y el rostro era donde se podía descubrir el reflejo de la honra derivada de la edad y de la valentía (López Austin, 1984).

En consecuencia, aquel personaje sepultado con un ajuar funerario y una máscara de piedra verde se contaba entre los elegidos de la sociedad maya, como lo indica la valía y el significado del material con el que se recreaban su rostro y cuerpo.

Durante el periodo Clásico, el complicado viaje al inframundo realizado por el dios de maíz y sus hijos tiene como fin último el origen del hombre y la creación de la humanidad (Taube, 1997). El ciclo de la muerte se ha vinculado a la sucesión del linaje real y el mantenimiento del equilibrio cósmico, que eran las 
dos cargas que pesaban sobre los hombros del gobernante. Las ceremonias que celebraban la muerte y resurrección del dios del maíz eran un conjuro contra la esterilidad, la extinción del grupo o la desaparición del rey, peligros que amenazaban la estabilidad del reino y la sobrevivencia de la comunidad.

El gobernante es el único y supremo sacerdote que establece una comunicación directa con los dioses y los ancestros. De allí que posea una dimensión cósmica: su cuerpo es la imagen del universo. Cuando accede al poder se le compara con el sol al amanecer, y cuando muere, con el sol en el ocaso. Es el personaje principal de los relatos históricos grabados en las estelas y su imagen es la receptora de las ofrendas y los sacrificios. Los ancestros que lo acompañan son los garantes de su legitimidad, y su figura es la representación de la comunidad y del reino (Baudez, 2002).

De esta forma, el personaje se mostraba a los ojos humanos con un carácter divino cuyas advocaciones estaban indicadas por los objetos de su atavío funerario. Tras su muerte, el gobernante iniciaba un viaje hacia el inframundo donde entraría en contacto con las deidades para interceder a favor de sus descendientes, con una fuerza sagrada y por lo tanto venerada. Así, con el ajuar que porta ya muerto, representa un vínculo cósmico entre los antepasados y sus descendientes, convertiéndose, por lo tanto, en un ancestro; un antepasado sagrado.

Por su parte, los dioses, con quienes los reyes interactuaban, no se distinguían en su conducta de los seres humanos, si bien eran más poderosos y grandes, pero otorgaban su protección y sus regalos sólo a cambio de favores. Así, los gobernantes realizaban varios rituales para que la comunidad pudiera utilizar los regalos divinos. En muchos de estos rituales los gobernantes se disfrazaban como las propias deidades, con atavíos que incluían máscaras particulares que jugaban una parte importante de la ceremonia. Visto de perfil se mostraba que el gobernante no era la divinidad misma (Martínez del Campo, op. cit.). De cierto modo podría decirse que los gobernantes funcionaban como un contenedor temporal de las fuerzas divinas. Lo que se esperaba de ellos no era que cambiasen el mundo sino que lo condujesen e hicieran los rituales necesarios para ello. En éstos hacían ostentación de su poder político y religioso. Sin duda ese papel jugaron los gobernantes masculinos de Palenque y Calakmul, que fungieron como una conexión entre el cielo, la tierra y el inframundo, pero también con la gente y la subsistencia.

Pero a la par de los gobernantes masculinos que registran la historia, la epigrafía y la arqueología maya, podemos hablar de mujeres gobernantes y sus tumbas; referirnos a ellas como capaces de ejercer el poder, fundar linajes o simplemente gobernar en nombre de sus hijos, hermanos o padres. El reconocimiento de los glifos femeninos en las inscripciones mayas, y el papel que jugaron las mujeres dentro de los sistemas de parentesco (linajes), como madres e hijas de los gobernantes, son algunos de los aspectos importantes, de los cuales tenemos información para el caso de ciudades mayas antiguas como Yaxchilán, Palenque, Naranjo, Edzná, Piedras Negras, Uaxactún, Bonampak, Calakmul y, de particular interés para nuestro estudio, Dzibanché. 
Es, por tanto, importante conocer el papel que representaban las mujeres en la sociedad maya; si sólo actuaban dentro del rango que las ubicaba como madres y esposas de los gobernantes y su papel se limitaba a la legitimación del poder a través de los ritos de legitimación y santificación del poder, o si también cumplían con otras tareas asociadas directamente con el poder.

Ya en 1961 Proskouriakoff señalaba que las mujeres mayas eran importantes dentro de la sociedad gracias a su papel como madres y esposas de los gobernantes. Además, eran parte de la dinastía en el poder no sólo por cumplir con tales papeles, sino también por medio de la descendencia y porque sus actividades, a más de los actos políticos y rituales, incluían algunas similares a las de los hombres, pues sus representaciones en los monumentos llegaron a ser equivalentes. Patricia McAnany presenta un análisis de los sistemas de linajes donde reitera que el nombre del linaje era patronímico, pero también se daba mucha importancia a los matronímicos, referidos como naal, como había postulado Roys en 1943 (McAnany, 1995).

En el caso del derecho a heredar el trono por vía materna tenemos también ejemplos en casos como el de Naranjo con la señora Wak Kanil Ahau, o bien Palenque con las señoras Kanal Ikal y Zac Kuk. Finalmente, es central para este trabajo señalar que las mujeres mayas sí llegaron a ejercer el poder como gobernantes. Esto lo podemos comprobar en Yaxchilán con la señora Balam Ix Witz y en Naranjo con Wak Kan Ahau (donde los elementos iconográficos asocian a estos personajes femeninos con el poder, pues portan la barra ceremonial, realizan actos de humillación y sacrificio de cautivos y llevan en sus nombres títulos semejantes a los masculinos), pero en el caso de Dzibanché tenemos a un personaje femenino en una tumba del Clásico Temprano, sin apoyo iconográfico o epigráfico alguno, ni glifos que indiquen su nombre. Entonces, la única manera para calificarla como ajaw es recurrir a los objetos que componen su ajuar funerario: la cerámica, los símbolos de poder como la concha grabada y el atavío funerario mismo.

\section{El atavío funerario}

El atavío funerario era una unidad indisoluble, de allí que la máscara funeraria de jade representara a la deidad de maíz con sus propios atributos pero con la fisonomía del gobernante, mientras que los mosaicos del cinturón y del pectoral representaban a la deidad misma como acompañante del soberano divinizado. Los objetos que lo formaban le conferían poder para ejercer como dios del maíz, Árbol del Mundo y centro del universo. Por lo tanto, él y su atavío —en el momento de la muerte y en el más allá- representaban un acto de renacimiento y creación.

Los atavíos funerarios mayas de jade integraban un conjunto simbólico de gran importancia. El texto que formaba este atavío, en el contexto funerario durante el ritual de inhumación, mostraba las características del soberano y los 
atributos de lo divino, así que estos materiales eran la esencia para denotar su naturaleza sobrenatural y su poder religioso y político.

\section{El jade: la conexión con el inframundo y otros significados}

El jade, según Martínez del Campo, tenía "una característica muy importante: la selva del Yucatán es muy húmeda y el jade es muy frío. Cuando le daba los primeros rayos del sol surgía vapor de la piedra y los mayas creían que estaba viva. Ese humo significaba la presencia de las fuerzas sobrenaturales dentro de la piedra y la utilizaban para crear objetos sagrados" (op. cit.: 232). Este material, como ya se señaló, simbolizaba el agua, el verdor de la naturaleza y, en general, la fertilidad con una simbología eterna de la renovación de la vida. Por ello, los objetos de prestigio político con la representación de lo sagrado tienen en común su elaboración con jade, el material más preciado para los mayas.

\section{El cinabrio}

Los cuerpos de los gobernantes mayas eran finalmente cubiertos con cinabrio, un mineral de intenso color rojo que, como ya dijimos, representaba el líquido vital, la sangre (Bernal, 2004). Según las creencias mayas, transfería sus cualidades regenerativas al gobernante fallecido y ayudaba conjuntamente con el jade en el proceso de resurrección.

\section{La concha}

Las conchas que formaron parte de los atavíos funerarios sirvieron para conformar pectorales, collares o sartales, y eran símbolos conectados con el inframundo y sus habitantes. Los mayas emplearon valvas y caracoles, pues buena parte de su territorio estaba rodeado por el mar; para ellos tenían una fuerte carga simbólica, relacionada con lo acuático y lo femenino; pensaban que eran sagrados. Así, la concha marina se convirtió no sólo en un adorno, sino en una insignia de alto rango para los gobernantes, representando objetos de poder.

\section{Máscara, orejeras, cuenta en la boca y psicoducto}

A través del pasaje del psicoducto el soberano era incorporado al universo de los ancestros. Como apuntamos, se le ha considerado como un umbral entre el inframundo y el mundo de los humanos y significa "que conecta el sarcófago con el mundo exterior" (Martínez del Campo, op. cit.). Por lo tanto la máscara y las orejeras forman un gran parte del mismo psicoducto metafórico. 
Si recordamos que la metáfora, en términos generales, es una variante de la analogía, y que, a decir de Tijus, la analogía es "una relación de dos objetos, fenómenos, situaciones que pertenecen a campos distintos, pero hacen pensar uno en el otro porque su desarrollo y aspecto presentan similitudes" (2003: 17), podemos conceptualizar a cada máscara como un segundo "yo", a través de la cual desaparece la naturaleza humana, permitiendo a su portador adoptar la naturaleza y las cualidades divinas.

Och b'ih, "entró en el camino", es, a decir de los epigrafistas, una de las expresiones de la muerte que también se relaciona con el renacimiento del alma a través del simbolismo de las orejeras, que son capaces de inhalar y exhalar humedad y aliento. Por esta razón se consideraban como pasajes del aliento del espíritu, en tanto que la cuenta de jade era el pasaporte hacia el cielo, para que el espíritu saliera por la boca.

\section{Objetos particulares}

K'inich Janaab' Pakal: en su sarcófago se encontraban objetos que no pertenecían al atavío funerario mismo pero que tampoco se pueden excluir. La figurilla de jade del dios Pax colocada junto a su pie izquierdo, y las cuatro cuentas de jade completaban la idea de un cosmos funerario completo. La deidad representaba al dios del Árbol del Mundo que acompañaba al soberano y atribuía la misma función al gobernante. Las cuatro cuentas cuadrangulares dan la impresión de que él directamente mantiene el equilibrio entre los estratos del universo.

Garra de Jaguar Yuknom Yich'aak K'ahk': Maricela Ayala se refiere al "bulto de poder" y al "bulto sagrado", pero en este caso tenemos un bulto funerario en contexto arqueológico. El primer bulto, a decir de la autora, se usaba en los casos de entronización: "En los casos de entronización lo que está envuelto es el c'ac'al"; "lo que se cuida, la corona, el gobierno"; "la majestad", o, a decir de los mexicanos, "el bulto que carga el gobernante, es el pueblo" (Ayala, 2002: 145). El mismo bulto contenía lo necesario para el autosacrificio, la purificación, el ritual al dios solar y el culto a los antepasados, y era ostentación del poder. Era "un Bulto de Gobierno que contenía las insignias de poder, que no eran otra cosa que los nombres de los dioses", mientras que el otro bulto sagrado contenía "pieles de tigre, lancetas de obsidiana, espinas de raya, cuerdas y hongos alucinógenos" (Ayala, op. cit.: 15). En este caso, sin duda, se puede decir que el ajuar funerario de Garra de Jaguar contenía la mayoría de estos objetos; por lo tanto, formaba un complejo texto metafórico y aportaba un equilibrio cósmico entre el poder y las costumbres.

El gobernante femenino: La concha de Dzibanché se distingue de otras grabadas e incrustadas por mantener más o menos su trazo natural y un dibujo geométrico en su exterior. Muestra a un gobernante sentado en un trono y cargando en sus manos una serpiente bicéfala, mientras de su boca emergen las cabezas de dos deidades. El dibujo es típico del Clásico maya, pues se repite en 
varias estelas, altares y objetos portátiles. Por lo tanto era fundamental para el personaje femenino, en tanto probaba su pertenencia a una dinastía real y que poseía poder divino. Puede apuntarse que en este caso podría ser un ajaw del Clásico Temprano.

\section{Consideraciones finales}

Como hemos visto, los atavíos funerarios se obtenían a través de una unión de teselas, cuentas, aplicaciones y otros objetos elaborados con jade, concha, caracol, obsidiana, hematita y materiales orgánicos de alta calidad. Para la sociedad maya, todo ello estaba simbólicamente relacionado con las divinidades. Los gobernantes, y los objetos sagrados que les acompañaban, se presentaban como imágenes de las deidades, generando un poderoso proceso de transformación que permitía a los seres espirituales encarnar a las personas, y a sus objetos convertirse en personificaciones de los seres sobrenaturales. Las prácticas del culto funerario a los ancestros, así como a las deidades que giraban en torno a éstos, tienen hondas raíces en la sociedad maya, que se materializan en las tumbas, pirámides, bultos sagrados, representaciones iconográficas y textos jeroglíficos.

Este culto funerario era parte integral de la cosmología y las prácticas de Estado. Los rituales mortuorios servían para dignificar a los antepasados y reconocer a los descendientes, a fin de otorgarles importancia social, cultural, política, ideológica y jerárquica. Los linajes estaban íntimamente relacionados con el culto a los ancestros, y muchas de las representaciones de éstos fueron identificadas como personajes femeninos por fray Diego de Landa, quien les denominó "ídolos" (Landa, 1985). Los ancestros eran percibidos como los protectores de sus descendientes y como guardianes de sus posesiones; fenómeno fácilmente trasladable a las inscripciones, donde vemos la insistencia por hablar de los fundadores del linaje (los ton ajaw, señores fundadores) y su relación, por una parte, con los dioses creadores y, por otra, con los gobernantes. Por lo tanto, el gobernante maya era una persona divinizada. El atavío funerario que usaba en el momento de la muerte no reflejaba sólo riqueza y prestigio, sino que era manifestación y síntesis de rango social, contexto ritual y persona sagrada.

Así, pues, los atavíos funerarios mayas de los gobernantes del periodo Clásico presentan un aspecto cosmológico del pensamiento maya y del universo mítico, sin olvidar que el texto particular que formaban se revela como una lectura compleja que ofrece numerosas respuestas para una mejor comprensión de la ideología y las creencias de esta civilización. 


\section{BIBLIOGRAFÍA}

Ayala Falcón, Maricela

2002 El bulto ritual de Mundo Perdido, Tikal. México: Universidad Nacional Autónoma de México, Instituto de Investigaciones Filológicas, Centro de Estudios Mayas (Cuadernos del Centro de Estudios Mayas, 27).

2010 "Bultos sagrados de los ancestros entre los mayas", Arqueología Mexicana 106: 34- 40.

Baudez, Claude F.

2002 Une histoire de la religion des Mayas: Du panthéisme au panthéon. Paris: Éditions Albin Michel.

Beliaev D., Dimitri y Alexander Safronof

2002 Kanal Kings in Quintana Roo. Manuscrito.

Bernal, Guillermo

2004 “K’inich Janaab’ Pakal, figura de culto de la dinastía de Palenque, Chiapas. La extinción de la flor blanca, entrar al camino", Arqueología Mexicana, 16 (especial): 18-21.

Campaña V., Evelia Luz

1995 "Una tumba en el templo de Búho, Dzibanché”, Arqueología Mexicana, 14 (III): 28-34.

Carrasco Vargas, Ramón

1999 "Tumbas reales de Calakmul. Ritos funerarios y estructura de poder". Arqueología Mexicana, 40: 28-31.

Fields, Virginia M. y Dorie Reents-Budet

2005 Los mayas, señores de la creación. Los orígenes de la realeza sagrada. México: Consejo Nacional para la Cultura y las Artes e Instituto Nacional de Antropología e Historia.

Freidel, David, Linda Schele y Joy Parker

2001 Maya Cosmos. Three Thousand Years on the Shaman Path. Nueva York: Williams Morrow.

García-Moreno, Renata y Josefina Granados G.

2000 "Tumbas reales, Calakmul. La gran urbe maya”, Arqueología Mexicana, 42 (VII): 28-33.

Landa, Diego de

1985 Relación de las cosas de Yucatán. México: Porrúa.

López Austin, Alfredo

1984 Cuerpo humano e ideología: Las concepciones de los antiguos nahuas. México: Universidad Nacional Autónoma de México.

Martin, Simon

2000 “Los señores de Calakmul”, Arqueología Mexicana, VII (42): 40-45. 
Martin, Simon and Nikolai Grube

2000 Chronical of the Maya Kings and Queens, Deciphering the Dynasties of the Ancient Maya. London: Thames and Hudson.

Martínez del Campo Lanz, Sofía

2010 Rostros de la divinidad, Los mosaicos mayas de piedra verde. México: Instituto Nacional de Antropología e Historia.

McAnany, Patricia

1995 Living with the Ancestors. Kings and Kingship in Ancient Maya Society. Austin: University of Texas Press.

Nalda, Enrique

1994 "Proyecto arqueológico Sur de Quintana Roo. Memoria de trabajos 19931994”, mecanografiado. México: Archivo Instituto Nacional de Antropología e Historia.

2006 "La concha grabada del edificio del Búho, Dzibanché”, Arqueología Mexicana, 82: 80-86.

Nalda Enrique y Sandra Balanzario

2005 "Kohunlich y Dzibanché: Los últimos años de investigación”, Arqueología Mexicana, 76: 42-47.

Proskouriakoff, Tatiana

1950 A Study of Classic Maya Sculpture. Washington, D.C: Carnegie Institution of Washington.

1961 "Portraits of Women in Maya Art", Essays in Pre-Columbian Art and Archaeology, pp. 81-99, Samuel Lothrop (ed.). Cambridge: Cambridge University Press.

Ruz Lhuillier, Alberto

1973 El Templo de las Inscripciones. México: Instituto Nacional de Antropología e Historia.

Stuart, David

2004 "La concha decorada de la tumba del Templo del Búho, Dzibanché", Los cautivos de Dzibanché, pp. 133-140. México: Instituto Nacional de Antropología e Historia.

Taube, Karl

1993 Aztec and Maya Myths. Austin: British Museum Press and University of Texas Press.

Tiesler, Vera y Andrea Cucina (eds.)

2003 Janaab' Pakal of Palenque: Reconstructing the Life and Death of a Maya Ruler. Tucson: University of Arizona Press.

Tijus, Charles

2003 Metaphores et analogies. Paris: Hermes Science.

Velásquez García, Erik

2004 "Los escalones jeroglíficos de Dzibanché", Los cautivos de Dzibanché, pp. 79-103, Enrique Nalda (ed.). México: Instituto Nacional de Antropología e Historia. 